\title{
El género de la novela en Marruecos: su delimitación y periodización
}

\section{The novel genre in Morocco: its demarcation and periods}

\author{
Francisco RODRÍGUEZ SIERRA ${ }^{1}$ \\ Universidad Autónoma de Madrid \\ franciscom.rodriguez@uam.es
}

Recibido: 13 de septiembre de 2013

Aceptado: 14 de mayo de 2015

\section{RESUMEN}

Este artículo aborda el papel que las diversas tendencias de la crítica literaria en Marruecos tuvieron en la configuración y delimitación del género de la novela, entendido éste como institución cultural dependiente de convenciones de orden cultural y social. Muestra, desde la etapa de formación del género y hasta finales del siglo pasado, cómo influyeron los cambios en los posicionamientos teóricos en el ámbito marroquí en la definición de los límites de la ficción y en qué debía entenderse como novela o como autobiografía, qué textos tenían cabida en el canon del género, sus propias fronteras y su periodización.

Palabras clave: literatura árabe, novela marroquí, género literario, canon.

\section{ABSTRACT}

This study broaches the role played by critical literary tendencies in Morocco upon the establishment and demarcation of the genre of the novel, which ought to be understood here as a cultural institution related to cultural and social conventions. Thus, this study poses, from the formation phases of the genre until the late years of the past century, how the theoretical positions had their influences, regarding the fiction limits, the difference between novel and autobiography, which texts enter the canon, and its own boundaries y periods.

Keywords: Arabic literature, Moroccan novel, literary genre, canon.

SUMARIO: 1. Introducción: sobre el género y su delimitación, 2. Los compendios bibliográficos, 3 . ¿Autobiografía o novela?, 4. La búsqueda del texto fundacional, 5. La periodización del género, 6. Comentario final.

\footnotetext{
${ }^{1}$ Grupo de Investigación de la UAM "F-082 Ideologías y Expresiones Culturales Árabes Contemporáneas - IEXCUL".
} 


\section{INTRODUCCIÓN: SOBRE EL GÉNERO Y SU DELIMITACIÓN.}

La naturaleza de los géneros literarios se ha erigido en una de las cuestiones fundamentales de la Teoría de la Literatura. Bastaría con referirnos a los estudios más conocidos para darnos cuenta de hasta qué punto la naturaleza del género literario ha sido motivo de reflexión y afecta a un sinfín de cuestiones relativas a la historia de las literaturas nacionales y al campo de la literatura comparada. Lo que se entienda por género tiene implicaciones en la delimitación y periodización de un género concreto, en la historia "nacional" del mismo, por así decir, y en sus relaciones internacionales y su imbricación en un ámbito más extenso de los estudios comparativos $^{2}$. La idea del género como "institución", como convención cultural inserta en una sociedad que responde a unas necesidades y pulsiones estilísticas y estéticas concretas, ha sido moneda común desde hace décadas, desde los estudios de Harry Levin y Wellek y Warren ${ }^{3}$. Otra cuestión es la distinción entre lo que Claudio Guillén denomina cauces de representación, a saber, modos de presentación y de expresión de los géneros, como la narración, la actuación y la enunciación lírica; y los géneros propiamente dichos: tragedia, epopeya, ensayo, etc ${ }^{4}$; que se corresponde con la distinción que establece Gérard Genette entre modos y géneros ${ }^{5}$, y con García Berrio cuando habla de la "inserción" de los géneros literarios históricos en las estructuras artísticas "universales" o "naturales".

Centrándonos en Marruecos, la discusión académica, y a veces con tintes políticos, en torno a la emergencia de géneros literarios modernos tiene que ver con el concepto teórico de la naturaleza de los géneros literarios, en la medida en que afecta a los límites. La cuestión del umbral, es decir, de la delimitación del comienzo de tal o cual género, ha sido y sigue siendo motivo de discusión y es seguro que siga variando, como ha venido ocurriendo hasta el momento, al hilo de los posicionamientos teóricos y las diferentes apreciaciones de los estudiosos. Roger Allen ha defendido recientemente la necesidad de revisar y reescribir la historia literaria de la novela marroquí en lengua árabe y ha advertido del carácter problemático de la misma noción de los principios del género ("on the most theoretical level [...] the very notion of 'beginngings' for literary genres is already highly problematic"), noción que implica la existencia de ejemplos fundacionales o "primeros ejemplos", algo asimismo problemático ("equally problematic"). Entiende Allen conveniente y

${ }^{2}$ Para un panorama de la cuestión, véase GARCÍA BERRIO, Antonio \& HUERTA CALVO, Javier, Los géneros literarios: sistema e historia, Madrid, 1999; AA.VV., Théorie des genres, Paris, Éditions de Seuil, 1986.

${ }^{3}$ LEVIN, Harry, "Literature as an Institution", Accent 6 (1946), 159-168. Y WELLEK, René \& WARREN, Austin, Teoría Literaria, Madrid 1966 [1948].

${ }^{4}$ GUILLÉN, Claudio, Entre lo uno y lo diverso. Introducción a la Literatura Comparada, Barcelona 1985 , pp. 163 y ss.

${ }^{5}$ GENETTE, Gérard, "Introduction à l'architexte”, en AA.VV., Théorie... 89-159 [1979].

${ }^{6}$ GARCÍA BERRIO, Antonio, Teoría de la Literatura. La construcción del significado poético, Madrid, 1994. 
útil poner el foco en los precedentes y las continuidades, más que en obras fundacionales y rupturas ${ }^{7}$, algo a lo que se apunta Fernández Parrilla, quien en su trabajo sobre la génesis de la novela marroquí describe una situación de lenta e inexorable evolución de un sistema literario "tradicional" a otro "moderno", donde el género de la qișșa, aún de contornos poco definidos en los años treinta del siglo XX y finalmente cohesionados en los años cuarenta, se conforma con elementos de géneros anteriores (riḥla, munāzara, maqāma, etc.), en un formato de maqāla o artículo periodístico por ser su plataforma de publicación principalmente la prensa escrita, pero con voluntad decidida y conciencia clara por parte de los creadores de estar dando lugar a un nuevo género prosístico más acorde con el momento político, social y cultural que se vivía en el Marruecos de la época9.

Como veremos seguidamente, la institución del género novelístico en Marruecos se configura por la crítica marroquí expresándose a través de los listados o bibliografias de novelas marroquíes. La elaboración de tales listados, su composición y la justificación que las suele acompañar, son una declaración de intenciones respecto al género. Decidir qué obras deben ser incluidas y cuáles no, $\mathrm{y}$, sobre todo, dónde comienza la bibliografía, implica la asunción de una posición teórica. También significa una voluntad de asentamiento de un canon del género novelístico en Marruecos. En algún caso será el fruto del esfuerzo personal por parte del estudioso; en otros, la publicación del listado vendrá avalada por instituciones culturales como la Unión de Escritores Marroquíes. Clave en la reflexión crítica marroquí ha sido la posición teórica respecto a la distinción entre autobiografía y ficción y la situación de los límites ficcionales. Como expondremos, los cambios y las modas teóricas han tenido su importancia, y ello se deja ver en el hecho de que textos como, por ejemplo, Fi-l-țfüla, de 'Abd al-Maŷîd bn Ŷallūn, o al-Zāwiya, de al-Tuhāmī alWazzānī, hayan sido considerados novelas o autobiografías al hilo de estos cambios, con la lógica repercusión en el canon, que se ha estirado o encogido según las épocas, para dar cabida o no a determinadas obras. Estas variaciones, que vienen a demostrar de alguna manera el carácter de institución cultural, basada en la convención de los agentes implicados (creadores, críticos, lectores, etc.; en suma, de toda la sociedad), han afectado a la delimitación de lo que denomino el "umbral de entrada" en el género, que muchos han deseado fijar sobre la base de un texto fundacional o inaugural. Finalmente, ofreceremos una periodización del género de la novela en lengua árabe en Marruecos teniendo en consideración las cuestiones abordadas a lo largo del artículo.

\footnotetext{
${ }^{7}$ ALLEN, Roger, "Rewriting literary history: the case of Moroccan fiction in Arabic", en The Journal of North African Studies, Vol. 16, no 3 (2011) 311-324, véase 312-315.

${ }^{8}$ FERNÁNDEZ PARRILLA, Gonzalo, La literatura marroquí contemporánea. La novela y la crítica literaria, Cuenca, Ediciones de la Universidad de Castilla La Mancha, 2006, 79 y ss.

${ }^{9}$ FERNÁNDEZ PARRILLA, Gonzalo, La literatura marroquí..., 75-78.
} 


\section{LOS COMPENDIOS BIBLIOGRÁFICOS}

Al principio de su opúsculo bibliográfico titulado al-Riwāya al-magribiyya bi-l'arabiyya, 'Abd al-Rahīm al-'Allām aborda la cuestión del comienzo del género novelístico en Marruecos, que puede expresarse explícitamente como la búsqueda del texto primero, el texto fundacional ${ }^{10}$. Comenta que ha sido éste un tema que ha mantenido ocupado a ciertos críticos interesados por la cuestión del nacimiento del género, y que las opiniones han sido diversas y cambiantes de acuerdo con las épocas. Así pues, los relatos Fi-l-Tufüla (De la niñez, 1956); Dafannā al-māḍ̂̀ (Hemos enterrado el pasado, 1966), de 'Abd al-Karīm Ġallāb; al-Gurba (El exilio, 1971), de 'Abd Allāh al- 'Aruwī; o al-Zāwiya (La Zagüiya, 1942), han merecido cada uno, en diferentes momentos y por diferentes grupos de críticos, el honor de ser considerados ese anhelado texto fundacional.

Un vistazo a algunas de las bibliografías sobre las novelas árabes en Marruecos muestra una reveladora disparidad de criterios en decidir el "umbral de entrada", por así decir. Muștafá Ya là publicó en 1984 una bibliografía en la que las primera obras reseñadas eran, por este orden ${ }^{11}$ : al-Rihla al-marrakūsisiyya, Muḥammad bn Muḥammad bn 'Abdallāh al-Muwaqqit (1930) ${ }^{12}$; Tāhā, de Aḥmad al-Ḥasan al-Sakūrī (publicada por entregas en mayo de 1941, y luego recogida en un volumen en Larache en el mismo año) $)^{13} ;$ al-Zāwiya, de al-Tuhāmī al-Wazzānī (1942) ${ }^{14}$.

Otra bibliografía es la que aparece en 1985 en un conocido libro de Hamīd Laḥmidānī sobre la novela de expresión árabe en Marruecos ${ }^{15}$. Recoge novelas aparecidas hasta 1982 y, según el autor, viene a corregir las anteriores de Ibrāhīm al-Jațīb y de Țankūl y al-Mawzūn̄în. Las primeras obras son: Ruwwād al-maŷhūl, de Ahmad 'Abd al-Salām al-Baqqālī (al-Mațba'at al-'Ālamiyya, El Cairo, 1956); y Fi-l-Ṭufüla, de 'Abd al-Maŷīd ibn Ŷallūn (Maṭba'at al-Aṭlas, 1957). Finalmente, la bibliografía

${ }^{10}$ AL-'ALLĀM, 'Abd al-Raḥim, l-Riwāya al-magribiyya bi-l-'arabiyya. Min al-ta'sīs ilà alimtidādāt. Bībliogrāfiyya: 1942-1999, Manŝūrāt Ittiḥād Kuttāb al-Magrib, 2000; véase p. 6.

${ }^{11}$ YA LÀ, Muștafá \& MUWADDIN, 'Abd al-Rahīm, "Bībliyūgrāfiyya al-fann al-riwā'̄i bi-1Magrib (1930-1984)", Áfāq, diciembre (3-4), 1984, 74-82. Ya alá menciona bibliografías anteriores en las que se basa en parte para elaborar la suya propia; y son las de Ibrāhīm al-Jațīb, en Aqlām , 4 (febrero), 1977; Muhammad al-Iḥsāynī en al-Madīna, 4-5 (junio), 1979; Tankūl y al-Mawzūnī (en francés), en Europa, junio-julio, 1979; y en al- 'Alam al-Taqäfì, no 694, 19/05/1984.

${ }^{12}$ Publicado en Maṭba at al-Bābī al-Ḥalabī wa-Awlādi-hī, El Cairo, en 1930, y no en 1940 como mantiene 'Azzām (véase YA'LÀ, Muștafá \& MUWADDIN, 'Abd al-Rahị̄m, "Bībliyūgrāfiyya...”, 75).

${ }^{13}$ Publicado en la revista al-Wahda al-Magribiyya, a partir del no 180, 9 de mayo de 1941. Luego bajo el título Dos relatos marroquies [Qișsatān magribiyyatān] en la editorial Maṭba at al-Funūn alMușawwara, Boskā, Larache, en 1941, junto al relato de un escritor español (véase YA LÀ, Muștafá \& MUWADDIN, 'Abd al-Rahīim, "Bībliyūgrāfiyya...", 75).

${ }^{14}$ En Manŝūrāt Maktabat al-Naŝr, Maṭba at al-Rīf, Tetuán (véase YA LÀ, Muștafá \& MUWADDIN, 'Abd al-Rahīm, "Bībliyūgrāfiyya...,", 75).

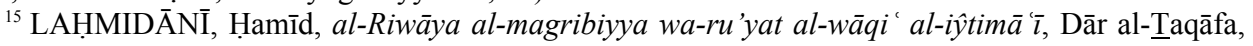
Casablanca, 1985, 549-551.

${ }^{16}$ Véase AL-HAṬīB, Ibrahīm, al-Aqlām, 4 (febrero), 1979, 28; y "Bibliographie des oeuvres en langue arabe (Roman)", en Europe, juin-julliet, 1979, 181. 
elaborada por 'Abd al-Rahīm al-'Allām ${ }^{17}$ se inicia con al-Zāwiya (1942); y Wazīr Garnāta de 'Abd al-Hādī Būṭālib (Maṭba at al-Istiqāma, El Cairo, 1950).

Las discrepancias entre estas bibliografías son el reflejo de los posicionamientos de la crítica hacia el género ${ }^{18}$. Comenzando por Ya là, el propio crítico asume que su listado no sólo recoge novelas:

Hemos introducido en el listado todas las obras que contribuyen a formar una imagen real de la evolución del arte novelístico [al-fann al-riwāân] en Marruecos, una evolución surgida de la reproducción de las formas (de la rihlla a la autobiografía, del cuento largo a la novela corta y a la novela larga, y, finalmente, a la novela corta otra vez), todo ello con el fin de facilitar la tarea de los estudiosos y los historiadores de la literatura ${ }^{19}$.

Más allá de esta aclaración, en el listado no se diferencia entre novela y lo que presuntamente no lo es, $\mathrm{y}$, de hecho, todo el material es introducido por la frase: "A continuación el listado de la novela escrita por marroquíes entre 1930 y 1984" (p. 75). En el mismo artículo hay una segunda parte, firmada por Muwaddin (pp. 7982), en la que se realiza un examen de esta bibliografía y se señala que a través de ella se evidencia la existencia de tres "tendencias novelísticas": la novela histórica, la autobiografía y la novela social. Esta matización, realizada en estos términos, no aclara demasiado el panorama y sólo viene a confirmar que, en la práctica, se han visto metidas en el mismo saco formas narrativas dispares.

Por su parte, Lahmidānī deja claro su concepto de novela y los criterios en los que se apoya para elaborar su bibliografía. Sobre el concepto sólo consigna la imposibilidad de establecer una definición viable de novela por parte de la crítica y llega a una solución de compromiso:

...podemos decir que la novela es lo que una mayoría de críticos en determinada época estudia como novela (...). Lo cierto es que el único denominador común de todos los tipos de novela es el ser un relato largo. Esta definición, pese a ser formalista, representa un denominador común mínimo en el que todas las novelas puedan converger, a pesar de que la delimitación de la longitud sea también relativa. ${ }^{20}$.

${ }^{17}$ AL-'ALLĀM, 'Abd al-Raḥim, l-Riwāya al-magribiyya , 21-40.

${ }^{18}$ Otra muestra de esta disparidad es la del profesor sirio Muhammad 'Azzām, quien ofrece una bibliografía de la novela marroquí "desde su nacimiento hasta la década de los ochenta" que se inicia con Fạṭima, de 'Abd al-'Azīz 'Abdallāh, e Inna-hā al-ḩayāt, de Muḥammad al-Bū' anānī (ambas sin datar y que 'Azzām coloca respectivamente en primer y segundo lugar sin aportar razones, cuando por bibliografías anteriores se sabe que la primera es de 1944 y que la segunda apareció, sin fechar, eso sí, a mediados de los setenta); Mudakkirāt dār faqūha, de Malīka al-Fāsī (1938); al-Rihla almarrākuŝiyya, de Muḥammad bn 'Abd Allāh al-Muwaqqit, (El Cairo, 1940); donde Fi-l-țufūla de 'Abd al-Maŷîd bn Ŷallūn (Mațba'at al-Ațlas, 1957), se encuentra en el número octavo de la lista; véase 'AZZĀM, Muḥammad, Wa'y al-'àlam al-riwā' $\bar{\imath}$. Dirāsāt al-riwāya al-magribiyya, Ittiḥād Kuttāb al-'Arab, Damasco, 1990, 257-262.

${ }^{19}$ YA 'LÀ, Muștafá \& MUWADDIN, 'Abd al-Raḥīm, "Bībliyūgrāfiyya...”, 74.

${ }^{20}$ LAHMIDĀNī, Hamīe, al-Riwāya al-magribiyya, 37. 
Sobre esta definición, su criterio para la elaboración de la bibliografía será la longitud ("80 páginas"), pero también lo que en el momento de la elaboración la crítica consideraba novelas. De este modo, bien por un criterio cuantitativo como de consenso crítico, todas las obras anteriores a Ruwwād al-maŷhūl (1956) y a Fi-l-tufüla (1957) ${ }^{21}$ caen de la lista: tanto autobiografías como relatos históricos más o menos breves.

En el caso de la lista propuesta por 'Abd al-Rahīm al-'Allām, llama la atención que las dos primeras obras sean al-Zāwiya (1942) de al-Tuhāmī al-Wazzān̄̄, y Wazìr Garnāța (1950) de 'Abd al-Hādī Būṭālib, dos obras mencionadas por al-Yabūrī en una cita anterior en la que eran calificadas respectivamente como destacados ejemplos de la autobiografía y de la novela corta histórica ${ }^{22}$. deja claro que su listado contiene junto a las novelas los textos autobiográficos, lo que explica, por ejemplo, la presencia de Zaman al-ajțā' de Muhammad Ŝkrî̉ ${ }^{23}$. Parece tener más sentido la presencia de Wazīr Garnāta, un relato breve histórico sobre la vida de Ibn al-Jațīb, por lo que al'Allām no se para a justificarla, pese a que pudiera ser considerado una novela breve, si se hace caso a al-Yabūrī. En resumidas cuentas, parece producirse un cambio de postura respecto a la bibliografía anterior y entronca con la intención de Ya là de elaboración de un listado que comprenda, junto a las novelas propiamente dichas, aquellos textos narrativos necesarios para entender el desarrollo del género novelístico; de alguna manera se trata de un canon explicativo, no normativo.

\section{3. ¿AUTOBIOGRAFÍA O NOVELA?}

Sobre la aceptación de Fi-l-țufüla como la novela marroquí que inaugura el género se pueden hacer algunas observaciones. La aparición de esta novela en libro al año siguiente de la independencia de Marruecos -es decir, en 1957- casaba con la corriente crítica ya descrita imperante en Marruecos que veía el surgimiento de la novela como el reflejo de unos condicionamientos sociales, políticos y culturales, y con la voluntad crear una literatura nacional. De esta manera se conseguía vincular muy estrechamente la emergencia del género con un período trascendental y con una fecha tremendamente significativa. La otra observación es la ya señalada por Azrūwīl en el sentido de que el consenso sobre Fi-l-tufüla era tal, que nadie:

mostraba cautela o precaución al expresar esta posición, por una parte, y que, por otra, algunos rechazaran todo carácter individualista que algunas novelas pudieran adoptar,

${ }^{21}$ Editada como libro en 1957, pero ya publicada por entregas en Risālat al-Magrib, algo recurrente en la gran mayoría de novelas de la época. No obstante, nos atenemos a las fechas que constan en las bibliografías.

${ }^{22}$ AL-YABŪRĪ, Aḥmad, Dīnāmiyyat al-nașs al-riwā' ’’, Rabat, Manŝūrāt Ittiḥād kuttāb al-Magrib, 1993, 26.

${ }^{23}$ AL-ŜĀĀI, 'Abd al-Qādir en su estudio de la autobiografía en Marruecos (al-Kitāba wa-lwuŷūd. Al-Sìra al-d̄âtiyya fi-l-Magrib, Casablanca, Ifrīqiya/ Ŝarq, 2000) aborda un examen pormenorizado de al-Zāwiyya y de Zaman al-ajțā', entre otras obras, y define la evolución del género en Marruecos en términos paralelos a la del género novelístico. 
y reprobaran el subjetivismo como eje de la labor novelística. Algunas de las críticas que se hacían a algunas novelas marroquíes es que eran meras autobiografías ${ }^{24}$.

Este hecho evidencia las contradicciones y el dudoso rigor de unos criterios focalizados en el contenido y en la postura ideológica del autor, vigentes en la crítica marroquí durante los setenta ${ }^{25}$.

Con la llegada de la década de los ochenta se produce el ya aludido cambio en la crítica en Marruecos y la superación del concepto sociológico anquilosado, centrado en el contenido, a una crítica basada en un concepto artístico y en un interés por las cuestiones formales y la estructura artística de la obra ${ }^{26}$. Es en estos momentos cuando se produce la alusión de atención de Barrāda sobre la necesidad de una relación feraz con el legado narrativo y de la relación entre formas modernas y tradicionales de narrativa.

Por lo que respecta a la autobiografía, la nueva década supone también la asimilación de la obra de Philippe Lejeune sobre la autobiografía, aparecida en $1975^{27}$, y cuya repercusión se evidencia en el congreso sobre la novela marroquí organizado por la Unión de Escritores Marroquíes cuyas ponencias fueron publicadas en el número 3-4 de la revista $\bar{A} f \bar{a} q$ en 1984, donde la mayoría de los artículos abordan la cuestión autobiográfica. Según Azrūwīl, a partir de la segunda mitad de los años ochenta aparecieron dos posiciones respecto a la cuestión autobiográfica. Una primera, representada por Hasan Baḥrāwī, quien reflexiona sobre el concepto de autobiografía sobre las bases teóricas de Lejeune y, en suma, sobre el pacto autobiográfico, que Baḥrāwī define como:

ese contrato que suscribe el autor con el lector con el fin de afirmar la identidad entre el autor y el héroe, y el recurso en todo al nombre personal escrito en la cubierta. Basta la existencia de este pacto en alguna de sus formas para que se produzca el descarte de toda posibilidad de ficción en la obra ${ }^{28}$. (44)

Esta posición sostiene la delimitación clara entre ambos géneros literarios, novela y autobiografía, gracias a ese pacto autobiográfico que a nivel pragmático se establece entre autor y lector.

La otra posición, según explica Azrūwīl, "hace uso del término 'autobiografía novelada' [al-sìra al-riwāi 'yya] y reconoce en principio la fusión entre los géneros literarios en obras concretas desde el nacimiento de la novela marroquí" "29. Esta posición planteó cuestiones respecto a la conveniencia de postular la veracidad o no de los acontecimientos narrados en la autobiografía. Azrūwīl allega afirmaciones de

${ }^{24}$ AZRŪWĪL, Fāțima, Mafāhīm naqd al-riwāya bi-l-Magrib, Casablanca, Fenek, 1989, 101.

${ }^{25}$ AZRŪWĪL, Fāṭima, Mafāhīm naqd..., 37.

${ }^{26}$ AZRŪWĪL, Fātịma, Mafāhīm naqd..., 53-54.

${ }^{27}$ LEJEUNE, Philippe, Le pacte autobiographique, París, Seuil, 1975. También del mismo autor L'autobiographie en France, París, A. Colin, 1971..

${ }^{28}$ BAHRRĀWĪ, Hasan, “Al-Sīra al-datiyya bi-l-Magrib namūdaŷan”, en Āfāq 3-4 (1984), 44.

${ }^{29}$ AZRŪWĪL, Fātịma, Mafāhīm naqd..., 102. 
Ḥamīd Laḥmidānī, como uno de los seguidores de estas corrientes, en las que se defiende la fusión del género de la novela y de la autobiografía: ésta "no se diferenciaría en mucho, de hecho, de la propia novela, puesto que nada impide que consideremos que ambas dos parten de la experiencia subjetiva de lo real para, tras ello, distanciarse en los límites de lo ficcional ${ }^{30 "}$.

Compárense estas dos posiciones en la crítica en Marruecos mencionadas por Azrūwīl (1989), con las que Pozuelo Yvancos presenta como las dos corrientes críticas en la actualidad (1993): “a) Quienes piensan que toda narración de un 'yo' es una forma de ficcionalización" y que plantea el intrínseco carácter ficcional del género autobiográfico; y b) quienes "aun admitiendo que algunas formas autobiográficas utilizan procedimientos comunes a la novela, se resisten a considerar toda autobiografía como una ficción" ${ }^{{ }_{31}}$. Como representantes de la primera opción estarían Barthes, De Man, Derrida y en general toda la deconstrucción; en el segundo caso, el representante más conocido es Lejeune y su concepto del pacto autobiográfico.

De este modo, la secuencia de la evolución de la crítica respecto a la autobiografía y, por tanto, de la cuestión de la aparición del género novelístico en Marruecos, comienza a clarificarse. En una primera etapa durante los años sesenta y setenta se produjo el largo consenso sobre el carácter de Fi-l-tufüla como primera novela en Marruecos. Como explica Azrūwīl, los críticos no intentaron abordar las relaciones entre los dos géneros (novela y autobiografía), sino que se lanzaron "a examinar las justificaciones -exteriores- que en opinión de ellos llevaban a los creadores a escribir sus autobiografías en determinados momentos históricos. Por ello se preocuparon por aclarar los datos sobre la realidad social y política a cuya luz pudiera entenderse que 'Abd al-Maŷīd bn Ŷallūn escribiera Fi-l-tufüla" ${ }_{32}$; a pesar de que, como hemos dicho, esta misma crítica mostrara una actitud negativa hacia las tendencias individualistas en los relatos. El consenso estaba establecido y perduró hasta los años ochenta.

Durante los años ochenta surgen las dos posiciones descritas hacia la autobiografía, negando o reconociendo carácter ficcional a este género. Se rompe entonces el consenso respecto a Fi-l-țufūla. De un lado, quienes como Hạīd Laḥmidānī opinan que los dos géneros se mezclan, y sitúa Fi-l-țfüla como obra que inicia el género. De otra quienes, como Aḥmad al-Madīnī, aunque reconociendo los valores literarios del relato de Ben Ŷallūn, afirma que se trata de una autobiografía y que es Dafannā al-māḍ̄ , de 'Abd al-Karīm Ġallāb, la obra que, en su opinión, "da cuerpo

${ }^{30}$ AZRŪWĪL, Fāṭima, Mafāhīm naqd..., 103; la cita la toma de Ḥamīd Laḥmidānī, Fi-l-tanẓīr wal-mumārasa: dirāsāt fi-l-riwāya al-magribiyya, Manŝūrāt 'Uyūn, 1986. Véase los capítulos introductorios sobre cuestiones teóricas en AL-Ŝ̄ĀWī, 'Abd al-Qādir, al-Kitāba wa-l-wuŷūd. Al-Sìra al-d̄ātiyya fi-l-Magrib, Casablanca, Ifrīqiya/ Ŝarq, 2000

${ }^{31}$ POZUELOS YVANCOS, José Manuel, Teoría del Lenguaje Literario, Madrid, Gredos, 1993, 185-186.

${ }^{32}$ AZRŪWĪL, Fāṭima, Mafāhīm naqd..., 100-101. 
a las características completas de la novela de Marruecos" ${ }^{{ }_{33}}$, ya que obras anteriores como Fi-l-tufüla, Sab 'at abwāb y Ruwwād al-maŷhūl se enmarcan dentro de la corriente autobiográfica; de este modo,

la consecuencia teórica de esta propuesta reside en que la autobiografía supuso, en una etapa concreta, que quizás no ha terminado aún [1985], el molde artístico y la ecuación objetiva apropiados para las inquietudes de escritores en una fase en la que la novela marroquí estaba por llegar ${ }^{34}$.

El cambio en los fundamentos teóricos que hemos descrito trae consigo un cambio en el concepto de novela, por el que

el crítico concede importancia al aspecto formal de la novela e intenta penetrar en su estructura artística (...) no se limita a lanzar juicios de valor tanto como descifrar la obra literaria (...) [y por el que] rehuyen poner un límite definitivo a la novela y reconocen la multiplicidad de tipos novelísticos y su variedad de acuerdo con las sociedades y las épocas ${ }^{35}$;

y conlleva la distinción teórica clara entre novela y autobiografía, pero también supone observar en las obras precursoras, como defendía Barrāda, "sus elementos compositivos y estructurales con prolongaciones en los desarrollos cuentísticos y novelísticos posteriores, válidos para constituirse en elementos dialógicos, en sentido profundo, dentro de la novela árabe moderna" ${ }^{36}$. Es desde esta posición desde la que partió Aḥmad al-Yabūrī al reivindicar, tanto en aquel número de $\bar{A} f a \bar{q}$ de 1984 en escritos suyos posteriores ${ }^{37}$, unos antecedentes del género novelístico en Marruecos encarnados en al-Zāwiya y en relatos históricos como los Benabdallah.

Mantiene al-Yabūrī que al-Zāwiya es "el primer producto semi-novelístico en Marruecos" y que "[L]a inserción de La Zagüía entre este tipo de textos permitiría definir las constantes y las variables de este género literario durante un período determinado, pero no permitiría establecer la especificidad de la obra, que debe

${ }^{33}$ AL-MADĪNĪ, Ahmad, Fi-l-adab al-magribī al-mu āșirir, Casablanca, Dār al-Naŝr al-Magribiyya, 1985.

${ }^{34}$ AL-MADĪNĪ, Ahmad, Fi-l-adab..., 43.

${ }^{35}$ AZRŪWĪL, Fāṭima, Mafāhìm naqd..., 54.

${ }^{36}$ BARRĀDA, Muḥammad, "Riwāya 'arabiyya ŷadīda", en al-Ādāb 3-2 (1980), 4. Nótese hasta qué punto se corresponde esta idea con la ya aludida teorización bajtiniana en torno a la distinción entre géneros discursivos primarios y secundarios y la interacción entre éstos (véase BAJTÍN, Mijáil, Estética de la creación verbal, Madrid, Siglo XXI, 1997², 248 y ss.). Véase YAQṬĪN, SA '̄̃d, alRiwāya wa-l-turāa al-sardī. Min aŷl wa '̇ yadìd bi-l-turāt, Casablanca, al-Markaz al-Taqāfī al-'Arabī, 1992, como un ejemplo práctico y efectivo de estudio de la intertextualidad para el caso árabe. Sobre la intertextualidad literaria, véase MARTÍNEZ FERNÁNDEZ, José Enrique, La intertextualidad literaria, Madrid, Cátedra, 2001

37 Véase AL-YABŪRĪ, Aḥmad, "Takawwun al-hnițāb al-riwā'̄. Al-Riwāya al-magribiyya namūdaŷan", en Âfāq 3-4 (1984), 13-19, traducido al español por Gonzalo Fernández Parrilla como "La génesis del discurso novelesco: la novela marroquí como modelo", en El Magreb y Europa: literatura y traducción, Cuenca, Ediciones de la Universidad de Castilla La Mancha, 1999, 201-210, cuya traducción seguimos aquí; y AL-YABŪRĪ, Aḥmad, Dīnāmiyyat al-nașs..., 1993. 
situarse en su contexto socio-cultural" ${ }^{13}$. Según al-Yabūrī esta obra, una autobiografía, presenta elementos que lo diferencian de la tradición autobiográfica anterior. El primero se muestra en las famosas primeras líneas de la obra, en las que un reiterado uso de la primera persona marcan formalmente la obra como autobiografía, pero al mismo tiempo, plantea la narración de unos hechos vividos como un conflicto entre el individuo, de una parte, y un ambiente heredado:

$\mathrm{El}$ ambiente tiene un poder que afecta a los espíritus; el medio posee un control absoluto en la dirección del hombre hacia un determinado aspecto de su vida. Si en estos folios deseo hablar de una de las páginas más hermosas de mi vida, como es la vida de retiro y de dedicación a la oración y la entrega a aquello que purifica y cultiva el alma, no tengo más remedio que unir esta etapa con otra anterior en la que fui sufí por herencia. ${ }^{39}$

Dice al-Yabūrī a este respecto:

A este respecto hay que señalar que si La Zagüía, como institución, impone la asimilación del «yo» en la sociedad, la autobiografía, como género literario, resalta el «yo» y afirma su presencia y su singularidad. Esta contradicción entre el título y el exordio, entre la institución y el género literario, pone de manifiesto dos etapas fundamentales en la formación del texto: el tiempo de la vida y el tiempo de la escritura, la de una pseudoconciencia y el comienzo de la formación de una verdadera conciencia ${ }^{40}$.

El segundo elemento característico de al-Zāwiya es el fino uso de la ironía en la crítica contra visiones y puntos de vista de algunos de los personajes que aparecen en el relato; así, el texto construye "una visión concreta, para luego intentar demolerla de manera indirecta [a través de la ironía] (...); por tanto, no se convierte el registro de sucesos, a pesar de su importancia, en lo básico, sino la multiplicidad de imágenes mentales derivadas de las acciones (...)." ${ }^{\prime 4}$

Reivindicar el texto de al-Zāwiya en estos términos significa situarlo en el quicio que marca el distanciamiento de una tradición narrativa autobiográfica y el advenimiento de un género ficcional, y podría significar, como dice 'Abd al-Rahīm al- 'Allām, que "la novela entre nosotros [es decir, en Marruecos] es hija de la autobiografía, mientras que la autobiografía es hija de la novela en Europa" ${ }^{\prime 2}$.

${ }^{38}$ AL-YABŪRĪ, Aḥmad, "La génesis del discurso...", 206. Véase AL-ŜĀWĪ, 'Abd al-Qādir, alKitāba wa-l-wuŷu$d \ldots$, para un panorama de la evolución del género autobiográfico en Marruecos. Véase 'AQQĀR, 'Abd al-Ḥamīd, al-Riwāya al-Magāribiyya. Tahawwul al-luga wa-l-hițāb, Casablanca, Ŝarikat al-Naŝr wa-1-Tawzī' , 2000, 170, habla de tres momentos en la autobiografía en Marruecos: los momentos de al-Zāwiyya, de Fi-l-tufüla y de al-Jubz al-ḥâfí.

${ }^{39}$ AL-WAZZĀNĪ, al-Tuhāmī, al-Zāwiya, Tetuan, Tituán Asmir, 1999, 16.

${ }^{40}$ AL-YABŪRĪ, Ahmad, "La génesis del discurso...", 202-203.

${ }^{41}$ AL-YABŪRĪ, Aḥmad, "La génesis del discurso....", 203.

${ }^{42}$ AL-'ALLĀM, 'Ảd al-Rahīm, al-Riwāya al-magribiyya bi-l-'arabiyya. Min al-ta'sīs ilà alimtidādāt, Rabat, Manŝūrāt ittihạd kuttāb al-Magrib, 2000, 6. 


\section{LA BÚSQUEDA DEL TEXTO FUNDACIONAL}

'Abd al-Rahīm al-'Allām al principio de su opúsculo al-Riwāya al-magribiyya bi-l'arabiyya, concede cierta importancia al problema del principio del género novelístico en Marruecos y el papel de la autobiografía, así como la posibilidad de que la novela en Marruecos, al contrario que en Europa, provenga de la autobiografía. No creemos que la cuestión carezca de importancia. Pero el empeño en buscar y localizar la obra primera, la referencia sobre la que se construye por acumulación el género, puede llevar, a nuestro juicio, a errores si no se tiene en cuenta el propio concepto variable de género. En la medida en que hemos considerado el género literario una institución cultural, y por tanto histórica, la obra primera se someterá también a los vaivenes que sufra la institución en la que se incluya. A esto es a lo que se refería al-'Allām a hablar de los vaivenes del consenso sobre el primer texto novelístico de Marruecos entre Fi-l-tufüla, Dafannā al-māộ̀, al-Gurba y al-Zāwiya.

Partiendo de la distinción entre novela y autobiografía y sin mezclar géneros, parece existir cierto consenso de la crítica en que la primera novela marroquí moderna es Dafannā al-māḍ̄. Pues aunque se acepte la importancia de Fi-l-tufüla, la circunscripción de ésta en el marco de la autobiografía deja a la novela de 'Abd al-Karīm Gallāb como primer exponente del género. Así, Ahmmad al-Madīnī concederá que Fi-ltufüla constituye "el principio artístico de la novela marroquí", pero lo cierto es que Fi-l-tufüla de 'Abd al-Maŷīd bn Ŷallūn se inserta en el género de la autobiografía"; la tesis de al-Madīnī es que la autobiografía es el molde artístico de la pulsión narrativa que anticipaba la novela, pero es Dafannā al-māộ̀ "la que encarna, en mi opinión, las características totales de la novela de Marruecos" ${ }^{\text {"43 }}$. De alguna manera, la posición de al-Madīnī es común cuando se intenta casar la importancia concedida a Fi-l-țufüla con el hecho de que, en puridad, no es un relato de ficción ${ }^{44}$.

Muhammad Barrāda, en un texto crítico muy anterior fechado en $1969^{45}$, ya apuntaba una postura similar a la de al-Madīnī. El primer texto que estudia Barrāda es Fi-l-tufüla y comienza intentando explicar el hecho de que el primer texto novelístico fuera una autobiografía ${ }^{46}$. El segundo texto examinado es Dafanna al-mā $\bar{c} \bar{\imath}$

${ }^{43}$ Véase AL-MADĪNĪ, Aḥmad, Fi-l-adab..., 42-44.

${ }^{44}$ Sobre esta cuestión comenta Roger Allen: "In Morocco, for example, 'Abd al-Majīd ibn Jallūn (b. 1919) published his novel Fì al-Tufüla ('In Chilhood') in 1957. The distinct tendency towards the autobiographical is much an evidence here as in earlier works; indeed such is the attention to detailed descriptions of life in the English city of Manchester, that, in spite of Ibn Jallūn's efforts to lend his novel some degree of fictionality, it seems most closely related to a work of travel such as al-Ṭahtāini Tajlịs alibrīz (...)" (ALLEN, Roger, "The Mature Arabic Novel Outside Egypt", en Modern Arabic Literature. The Cambridge History of Arabic Literature, M. M. Badawi (ed.), Cambridge UP, 1992, p. 205).

${ }^{45}$ BARRĀDA, Muhammad, "al-Usus al-naẓariyya li-l-riwāya al-magribiyya al-maktūba bi-l'arabiyya", en al-Riwāya al-magribiyya, 'Abd al-Kabīr al-Jațībī (coord.), Manŝūrāt al-markaz alŷāmi '̄i li-l-baḥtąal- 'ilmī, Rabat, 1971 [1969], 141-149.

${ }^{46}$ Fātịma Azrūwīl alude a esta cuestión: "Esta afirmación no llevó a los críticos a estudiar la relación entre estos dos géneros literarios [novela y autobiografía] como elementos diferenciados cuyo componentes podrían cruzarse y la naturaleza de estos componentes, en la medida en que les llevó más 
(1966) y el tercero es Ŷ̄il al-ẓama' (1967), de Muhammad 'Azīz al-Ḥabābī, para pasar en el último apartado a repasar una serie de novelas que considera "fracasadas", a saber: Amțār al-raḥma (1965), de 'Abd al-Raḥmān al-Marīn̄i; Gadan tatabaddal al-arḍ (1967), de Fāṭima al-Rāwī; Būtaqat al-hayāt (1966), de al-Bakrī Ahmad al-Sibā '̄í y Inna-hā al-hayāt (sin fecha, pero probablemente a mediados de los sesenta), de Muhammad al-Bū 'nānī. Las razones de Barrāda para este duro calificativo son de índole formal: "penuria técnica" [al-iqdā al-fannī] y carencias en la "asimilación del desarrollo de la novela árabe" ${ }^{47}$. Estas novelas "fracasadas" son publicadas en el período que media entre la aparición de Fi-l-țfüla y Dafannā al$m \bar{a} d \underline{\imath} \bar{i}$, el mensaje que, en el fondo, quiere hacer llegar Barrāda -o, al menos se colige de este planteamiento de las cosas- es que, al igual que opinaría al-Madīnī varios

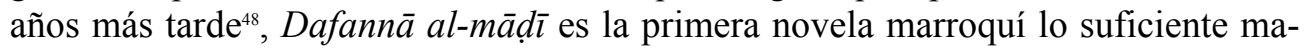
dura como para generar epígonos que den forma a un género.

El propio concepto de género, que asumimos, como institución cultural, y por tanto social e histórica, requiere una cierta perspectiva para decidir qué texto es que el marca el referente; porque en este caso no se trata de dilucidar el primer texto, sino la referencia. Si Fi-l-tufüla, con sus cualidades artísticas, es una autobiografía, y las novelas fracasadas no pueden constituirse en modelo ${ }^{49}$, parece que Dafannā al-mā $\bar{d} \bar{\imath}$ se yergue como el texto que inaugura institucionalmente el género en Marruecos. Cuando 'Abd al-Ḥamīd 'Aqqār, en un texto del año 2000, decide que Dafannā al-mā rruecos" ${ }^{50}$, expresa muy bien la idea de que lo importante no es el primer texto, sino el que marca la pauta a seguir. Como dice Claudio Guillén, "Sólo el tiempo histórico puede demostrarnos que un modelo ha llegado efectivamente a erigirse en género" "si ; los precedentes de Dafannā al-mā ḍ̆, o no eran ficción o no eran modelos plausibles. Cuando el crítico egipcio Ŷābir 'Așfūr aborda los comienzos del género de la novela en Marruecos alude también a los precedentes que no acaban de cuajar pero que preparan el advenimiento de las primeras obras plenamente novelísticas:

El texto insertable en el género de la rihla al que pertenece Mir'ät al-masā' '̄ alwaqtiyya (1923) de Muhammad bn 'Abd Allāh al-Mu'aqqit; los comienzos prematuros al que pertenece al-Zāwiya (1942) de al-Tuhāmī al-Wazzānī; o los intentos

bien a estudiar las justificaciones -exteriores- que explicarían, en opinión de ellos, que los creadores se vieran dirigidos a escribir sus autobiografías en una etapa histórica concreta" (AZRŪWĪL, Fāțima, Mafāhìm naqd..., 100).

${ }^{47}$ BARRĀDA, Muḥammad, “al-Usus al-naẓariyya...,", 147.

${ }^{48}$ AL-MADĪNĪ, Aḥmad, Fi-l-adab..., 44.

${ }^{49}$ Dice Barrāda de estas novelas fracasadas: "Esta ola de novelas romántico-dramáticas no encontró aceptación ni eco entre el público lector marroquí, formado en su mayoría por estudiantes, docentes y profesores universitarios, un público que se identificaba más con las novelas de Naŷīb Maḥfūẓ. Eso es lo que nos hace considerar estas novelas un 'retroceso' a una etapa social y artística ya superada" (BARRĀDA, Muḥammad, "al-Usus al-naẓariyya...", 148).

50 'AQQĀR, 'Ảbd al-Hamīd, al-Riwāya al-Magāribiyya ..., 24.

${ }^{51}$ GUILLÉN, Claudio, Entre lo uno y lo diverso..., 150. 
novelísticos publicados por Aḥmad 'Abd al-Salām al-Baqqālī en El Cairo en 1956 (Ruwwād al-maŷhūl, Salāsil al-diahab), y los de 'Abd al-Maŷīd bn Ŷallūn, 'Abd alHādī Būtālib, e Ismā '̄il al-Bū'nānī en Casablanca y Rabat entre 1957 y 1963, no son sino intentos y comienzos que anticiparon la posibilidad de formación del género de la novela en Marruecos y que prepararon el camino para logros pioneros e influyentes que comenzaron, a mi entender, con la primera obra de 'Abd al-Karīm Gallāb (Sab 'at $a b w a \bar{b}$, 1965), Janāta Bennūna (al-Nār wa-l-Ijtiyār, 1966), Muhammad 'Az̄̄z alHabābī (Ŷ̀l al-zama', 1967) y 'Abd Allāh al- 'Arwī (al-Gurba, 1971)..$^{52}$

Y pese a que 'Așfūr, de manera incomprensible, olvide Dafannā al-māḍ̂, la coincidencia general de su análisis con el de la crítica marroquí es evidente.

\section{LA PERIODIZACIÓN DEL GÉNERO}

Respecto a la periodización del desarrollo del género novelístico en Marruecos, se suele contemplar un primer período de formación o nacimiento, correspondiente a los antecedentes del género, fase que suele datarse hasta mediados de los sesenta y que en ocasiones no se tiene en cuenta al considerarse que queda fuera del marco del género; una segunda fase de fundación, hasta finales de los años setenta y principios de los ochenta; y una tercera y última de experimentación $n^{53}$.

En un artículo de 1980, Muhammad 'Izz al-Dīn al-Tāzī analiza la producción novelística en Marruecos desde mediados de los años sesenta hasta finales de la década de los setenta ${ }^{54}$. El objeto del artículo es, en principio, hacer un repaso de los quince años de género novelístico, pero al-Tāzī aporta, desde la perspectiva de la nueva década que comienza y en la que se inaugurará una nueva etapa del género en Marruecos, una visión de la evolución de la novela marroquí en la que se diferencian claramente dos etapas hasta 1980, la fecha de artículo.

El primer período, que denomina "fase de partida" [marhalat al-ințilāq], se iniciaría a mediados de los sesenta. Describe al-Tāzī un contexto histórico postindependencia con un conflicto social y político en curso entre grupos sociales perjudicados y beneficiados por lo que califica de "independencia usurpada"; y en el que la mayoría de los escritores pertenecían a la pequeña y mediana burguesía y

52 'AȘFŪR, Ŷābir, Zaman al-riwāya, El Cairo, al-Hay'a al-Mișriyya al- 'Āmma li-l-Kitāb, 1999, 319-320. La novela de Bennūna no fue publicada en 1966, pese a la afirmación de 'AȘFŪR, sino probablemente en 1969, pese a que es una edición sin fecha. Así lo afirman AL-'ALLĀM, 'Abd alRahīm, al-Riwāya al-magribiyya...”, 22; y YA'LÀ, Muștafá \& MUWADDIN, ‘Abd al-Rahīm, "Bībliyūgrāfiyya...", 77; y refrendado en YA'LÀ, Muștafá, al-Sard al-Magribī 1930-1980. Bībliyūugrāfiyya mutajașsișa, Casablanca, Šarikat al-našr wa-l-tawzī' al-Madāris, 2002, 95.

${ }^{53}$ Véase, por ejemplo, 'AZZĀM, Muhammad, Wa'y al-'álam..., 10-11 y 242, donde el crítico sirio habla de fases de nacimiento, fundación y experimentación; y DAGMŪMĪ, Muhammad, al-Riwāya almagribiyya wa-l-tagayyur al-iŷtimā ${ }_{1}^{1}$, Casablanca, Afrīqiyā/Ŝarq, 49-52), quien propone fases, a saber, de imitación y de experimentación.

${ }^{54}$ AL-TĀZĪ, Muhammad 'Izz al-Dīn, "al-Wāqi'î̀ wa-l-mutajayyil. Min jilāl 'alā'iq al-baḥt al-

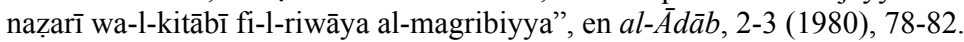


ofrecían una visión concreta de los hechos históricos, "que miraba a la historia como meros acontecimientos, y no en su dimensión dialéctica como extensión hacia el presente y el futuro"s5; al-Tāzī pone como ejemplos característicos las novelas de 'Abd al-Karīm Gallāb y de Aḥmad al-Bakrī al-Sibā'̄ì, entre las que la excepción de Ŷ̀l al-ẓam', de Muḥammad 'Azīz al-Habābī, no supone sino "un intento de un cierto desarrollo del estilo novelístico". Destaca al-Tāzī que la falta de apertura de los novelistas de esta primera etapa hacia otras experiencias novelísticas, tanto árabes como no árabes, dio como resultado, en su opinión, que "la mayoría de su producción adoleciera de incorrecciones de forma, de un estilo meramente informativo, más apegado a una narración de denuncia, en un marco tradicional imitador de obras de mala calidad, sin la ambición de generar un momento creativo acorde a la realidad mediante la conjunción de la realidad con lo artístico"s6; acto seguido alTāzī pone como ejemplos de estas novelas deficientes las novelas que Barrāda calificó once años antes de "novelas fracasadas"

La segunda fase se iniciaría, de manera difusa, con la aparición de una serie de novelas que suponen un salto en el desarrollo del género en Marruecos. Se refiere al-Tāzī a las novelas de Muhammad Rabī' (al-Tayyibūn [1971]; Rifqat al-silāh wal-qamr [1976]; al-Rīh al-sitī̄wiyya [1978]8) 'Abd Allāh al-'Arwī (al-Gurba [1971]; al-Yatīm [1978] ${ }^{59}$ ) y Aḥmad al-Madīnī (Zaman bayn al-wilāda wa-l-hulm [1976]), en las que ve "elementos de búsqueda formal en un marco de explosión de la lengua". Habría que mencionar también que la década de los setenta viene marcada por la relativamente prolífica producción novelística de Muhammad Zafzāf con alMar'a wa-l-warda (1972), Arșifa wa-ŷudrān (1974), Qubūr fi-l-mā' (1978), al-Af'à wa-l-baḥr (1979) ${ }^{60}$. Recuerda al-Tāzī que fueron las novelas que iniciaron este pe-

${ }^{55}$ AL-TĀZ̄̄̄, Muḥammad 'Izz al-Dīn, “al-Wāqi'ī wa-l-mutajayyil...”, 79. Muḥammad alDagmūmī ha estudiado las condiciones socioeconómicas y culturales de los escritores marroquíes a lo largo del desarrollo del género; véase DAGMŪMĪ, Muḥammad, al-Riwāya al-magribiyya..., sobre todo pp. 53 y ss.

${ }^{56}$ AL-TĀZ̄̄ Muhammad 'Izz al-Dīn, "al-Wāqi 'ī wa-l-mutajayyil...”, 79.

${ }^{57}$ Véase BARRĀDA, Muḥammad, "al-Usus al-naẓariyya...".

${ }^{58}$ Sobre al-Rīh al-siitāwiyya, dice Aḥmad al-Madīnī: "Es la primera obra novelística en Marruecos que muestra la preocupación de su autor por la narración realista y por el carácter de su visión social (....)" (AL-MADĪNĪ, Ahmad, Fi-l-adab..., 45).

${ }^{59}$ Dice al-Madīnī de al-Gurba y al-Yatīm :“...son dos auténticas contribuciones que viajan en la memoria y escarban en el suelo social. Aunque en ellas dominen la abstracción mental y la intensidad de la oscura observación psicológica, conservan la calidad novelística y la habilidad estructural, con el sometimiento de la narración novelística a una robusta prosa poética." (AL-MADĪNĪ, Aḥmad, Fi-l$a d a b \ldots, 47)$.

${ }^{60}$ Muhammad Barrāda añade, por su parte, a al-Tāzī como otro más de los renovadores de los setenta, y enumera al-Gurba [1971], de Laroui; al-Mar'a wa-l-warda [1972], de M. Zafzāf; Zaman bayn al-wilāada wa-l-ḥulm [1976], de A. al-Madīnī; Abrāŷ al-madīna [1978], de M. I. Al-Tāzī. Parece claro que al-Tāzī evita mencionarse a sí mismo. Véase BARRĀDA, Muhammad, "Características de la experimentación en la novela marroquí desde la década de los setenta", en La traducción de la literatura árabe contemporánea: antes y después de Naguib Mahfuz, Miguel Hernando de Larramendi \& Luis 
ríodo (al-Gurba y Zaman bayn...) las que más intensamente evidenciaron esta investigación formal que podría haber partido "como una forma de superación del estilo narrativo tradicional de Gallāb (...). Es un conflicto entre textos, y podría ser la encarnación de otro conflicto entre lo tradicional y lo vanguardista" ${ }^{61}$.

Nota al-Tāzì que en la primera etapa descrita las novelas parecían surgir aisladas unas de otras, pues, incluso en los casos de coincidencias temporales en las fechas de publicación las diferencias eran totales entre unas y otras; algunas obras no llegaron a tener repercusión alguna (las novelas fracasadas a las que aludía Barrāda); y que en la segunda fase la producción novelística quedó

fuera de todo desarrollo piramidal que pudiera dar lugar a un desarrollo cuantitativo, a pesar de la publicación de novelas sobresalientes $-\mathrm{y}$ que lo seguirán siendo a lo largo de la experiencia novelística marroquí, pues junto a éstas aparecieron otras novelas que partían de la pobreza artística y el desconocimiento de los instrumentos de la técnica novelística, incluso desde lo tradicional ${ }^{62}$.

Este panorama apuntado por al-Tāzī es el que intenta explicar al-Madīn̄̄ al afirmar que a lo largo de los años setenta la producción "no se atuvo a la lógica orgánica del propio género novelístico, sino que más bien fue una continuidad desorganizada, y las propias alternativas artísticas fueron aleatorias más que gobernadas por una visión o unos rasgos narrativos sólidos" ${ }^{63}$. En resumidas cuentas, que a la escasa producción se unía el hecho de que prácticamente cada escritor constituía él solo una corriente propia, lo que impedía una acumulación de obras que diera cuerpo a hipotéticas corrientes dotadas de cierta cohesión.

A comienzos de la década de los ochenta se inicia una nueva etapa en el desarrollo del género en Marruecos que ya supo ver Sa 'īd Yaqțīn en su libro al-Qirā'a wa-l-taŷriba (1985), donde analiza cuatro novelas que para este crítico marroquí ejemplifican unos cambios que, según él, habrían comenzado a aparecer a mediados de los setenta, pero que sólo "las transformaciones sociales y políticas de principios de los ochenta abrieron una ventana por la que las semillas brotaran y crecieran rá-

Miguel Pérez Cañada (coords.), Cuenca, Escuela de Traductores de Toledo/Universidad de Castilla La Mancha, 2000,. 281-289 (trad. de Rafael Ortega).

${ }^{61}$ AL-TĀZĪ, Muḥammad 'Izz al-Dīn, "al-Wāqi '̄̄ wa-l-mutajayyil...”, 80. Sobre Zaman bayn... dice al-Tāzì en este mismo lugar: "Partió de la ruptura con los modelos novelísticos escritos anteriormente. Esta ruptura consistió en el uso de instituciones nuevas del texto novelístico: la obsesión por el lenguaje, la impersonalidad, la sustitución de la narración y el diálogo por la aleatoriedad de la captación de los acontecimientos parciales y su formulación en un discurrir alocado ininterrumpido" (pp. 81-82). También Roger Allen: "The same innovative tendencies are evident in the work of the Morrocan novelist Muhammad 'Izz al-dīn al-Tāzī (b. 1948), Abrāj al-madīnah ('City towers', 1978) (...). Even more extreme in its innovative techniques is Zaman bayna 'l-wilāda wa'l-hulm ('Time between birth and dream', 1976) by another Morrocan novelist, Aḥmad al-Madīn̄i (b. 1948)." (ALLEN, Roger, “The Mature Arabic...”, 1992, 214).

${ }^{62}$ AL-TĀZİ, Muhammad 'Izz al-Dīn, "al-Wāqi 'ì wa-l-mutajayyil...”, 80.

${ }^{63}$ AL-MADĪNII, Ahmad, Fi-l-adab..., 47. 
pidamente" ${ }^{64}$. La característica dominante de la producción novelística de este período que se inicia sería, según Yaqtịn, "el intento de superación del período anterior (...), aunque esta superación difiera de escritor a escritor o de una experiencia novelística a otra" ${ }^{65}$. Yaqțin define la experimentación (al-taŷrīb) como "el prodigarse en el ejercicio de superación" ${ }^{\prime 6}$.

Yaqțin resume los rasgos del nuevo discurso novelístico en Marruecos en tres tendencias:

a) ruptura de la verticalidad de la narración [taksīr 'amūdiyyat al-sard], "de manera que el tiempo no se somete a la linealidad progresiva [al-jațtiyya altașā udiyya] en la que los acontecimientos se desarrollan y se implican al servicio de la trama argumental, sino que nos encontramos ante un tiempo que apunta a la ruptura de la lógica y la rutina del tiempo extratextual (pasado / presente / futuro) ${ }^{\prime \prime}$;

b) el entrecruzamiento de los discursos [tadājul al-jiṭābāt]: "el discurso novelístico acoge múltiples estructuras discursivas: dramática, lírica, religiosa, cuentística, oral, periodística, política, histórica, etc." ${ }^{\circ 8}$.

c) la dimensión fantástica [al-bu'd al- 'aŷa'ibī]: es una característica que Yaqțīn reconoce como secundaria, pero que en las novelas que estudia está presente en el seno de los diferentes discursos entrecruzados ${ }^{69}$.

Una opinión similar es la que expresa Muhammad al-Dagmūmī, quien divide los períodos por los que pasa la novela en Marruecos en dos: una fase de imitación [ta$q l \bar{l} d$ ] -hasta mediados de los sesenta- y otra de experimentación [taŷrīb]. Aclara alDagmūmī que:

${ }^{64}$ YAQȚĪN, Sa'īd, al-Qirā'a wa-l-taŷriba. Hawl al-taŷriba fi-l-jițāb al-riwā' $\bar{\imath}$ al-yadìd bi-lMagrib, Casablanca, Dār al-Taqāfa, 1985, 285. Las cuatro novelas estudiadas en este libro son: alAblah, al-Mansiyya wa-Yāsmīn (al-Mu'assasa al-'Arabiyya, Beirut, 1982) de al-Mīlūdī Sagmūn; Warda li-l-waqt al-magribī (Dār al-Kalima, Beirut, 1982), de Aḥmad al-Madīnī; Badr zamāni-h̄̄ (alMu'assasa al-'Arabiyya, Beirut, 1983), de Mubārak Rabī'; y Raḥil al-baḥr (al-Mu'assasa al'Arabiyya, Beirut, 1983), de M. 'Izz al-Dīn al-Tāzī.

${ }^{65}$ YAQTTITN, Sa 'īd, al-Qirā'a wa-l-taŷriba..., 287.

${ }^{66}$ YAQȚīN, Sa 'īd, al-Qirā'a wa-l-taŷriba..., 288. A un nivel árabe más amplio, vincula Yaq̣̣̂n esta tendencia con la superación, en el ámbito de la crítica novelística árabe, de la preocupación por la "función" de la literatura -desde los años veinte hasta incluso los sesenta- hacia la preocupación por la naturaleza de la literatura; supone, por otra parte, el planteamiento de nuevas preguntas y el paso de una visión filológica (con Ṭāhā Ḥusayn, al- 'Aqqād y al-Rāfíîi) a una visión arqueológica, en sus facetas de estudio de la estructura poética medieval (con Ŷamāl al-Dīn bn al-Ŝaj), la estructura narrativa medieval ('Abd al-Fattāh Kîl1̄ịtū), y la estructura ideológica ('Abd Allāh al-'Arwī, Muhammad 'Ābid al-Ŷābirī y Muhammad Arkūn, entre otros); véase también YAQṬ̂̄N, Sa 'īd, al-Qirā'a wa-l-taŷriba ..., 290.

${ }^{67}$ YAQȚĪN, Sa 'īd, al-Qirā'a wa-l-taŷriba $\ldots, 294$.

${ }^{68}$ YAQTT̄N, Sa ‘̀̃d, al-Qirā'a wa-l-taŷriba..., 295.

${ }^{69}$ YAQȚīN, Sa 'ìd, al-Qirā'a wa-l-taŷriba..., 296-297. 
imitación no se refiere a copia de ideas y contenidos, sino que se muestra: como lengua informativa narrativa que avanza según una línea horizontal, o como estilo literario abierto; como segmentación de acontecimientos y sucesos en episodios que dan a 'la historia' una importancia central: es el relato de una historia; como trama que hace que la novela tenga un final y que atraviese fases de acuerdo con una lógica previa ${ }^{70}$.

Al-Dagmūmī alude a la diferencia de calidad en las obras de este período y presenta como ejemplos negativos las ya conocidas "novelas fracasadas", pero afirma este autor que en todos los casos, la característica fundamental es la imitación de novelas aparecidas antes de 1965, "un modelo que en general era realista y con un fuerte componente sentimental" (p. 50).

La fase de experimentación se inicia, según al-Dagmūmī, a mediados de los setenta de la mano de algunos escritores vanguardistas. El componente experimental en estas novelas se reflejaría en:

a) La ruptura de la historia, haciendo que ésta se disgregue tanto dentro de la narración como a través de la línea temporal.

b) La mezcla de lo realista con lo fantástico, como un juego justificado por la fantasía.

c) Una lengua que pasa por la asociación de ideas y por el sueño para comunicar la fantasía.

d) La expresión explícita de posiciones de protesta hacia la realidad y la política.

e) Hacer flotar el personaje dentro de la novela para convertirlo en meras apariciones y voces difíciles de describir con precisión ${ }^{71}$.

Como puede observarse, las periodizaciones de Yaqțin y de al-Dagmūmī son en gran medida casables. La esencia del planteamiento es hacer ver que desde el momento en que arranca el género novelístico en Marruecos a mediados de los sesenta, tras un largo período de gestación desde la tercera década del siglo XX, existe un progresivo avance en la utilización de elementos narrativos vanguardistas, que acaban situándose como referencia de la actividad creadora.

\section{COMENTARIO FINAL}

Es de destacar que los artículos citados examinan períodos de tiempo relativamente breves debido a la tardía aparición de la novela en Marruecos: al-Tāzī estudia un arco temporal de quince años (hasta 1980) durante los que aparecen sólo unas 30 novelas; Yaqtịn escribe su libro cinco años después y los dedica precisamente a ese

\footnotetext{
${ }^{70}$ DAGMŪMĪ, Muhammad, al-Riwāya al-magribiyya ..., $50 .$.

${ }^{71}$ DAGMŪMĪ, Muḥammad, al-Riwāya al-magribiyya ..., 50-51.
} 
lustro, durante el que aparecen nada menos que 28 novelas (es decir, un número casi equivalente a toda la producción anterior).

Lo cierto es que la escasa producción hasta ese momento facilita la impresión de un género deslabazado, donde cada autor, como apuntaba al-Madīnī, parece encarnar una corriente o tendencia por sí mismo. Según al-Dagmūmīī, el desarrollo del género

no puede considerarse que brote desde el interior de propio género novelístico como resultado de sus diferentes acumulaciones, sino que se debe a un elemento cultural voluntarista (...), es decir, vinculado con un deseo cultural al que los críticos se refieren con el término 'modernidad' [hadāta] o, en líneas generales, como renovación $[t a \hat{y} d \bar{\imath} d]^{72}$.

En un contexto en el que la producción era tan escasa, al menos hasta la década de los ochenta, la aparición de un número de novelas vanguardistas fue suficiente como para que se percibiera el cambio de rumbo.

En nuestra opinión habría que interpretar este desarrollo, más allá de las segmentaciones en etapas o períodos más o menos definidos, sencillamente como un asentamiento del género, que había de pasar necesariamente por una acumulación progresiva de obras (de hecho, ha sido casi exponencial) y una diversidad y maduración de las técnicas narrativas, que a su vez requeriría un mayor contacto con la producción novelística de fuera de Marruecos, tanto del mundo árabe como de fuera de éste. De hecho, el propio Yaqțin presenta las etapas de desarrollo y las características que hemos apuntado como comunes al mundo árabe en general. En el caso marroquí, la diferencia estriba en el tardío surgimiento del género, pero desde ese momento hasta la aparición de los primeros ejemplos de novelas vanguardistas en Marruecos apenas median seis o siete años, desde Dafannā al-mā $\bar{d} \bar{l}$, de 1966, hasta al-Gurba, de 1971. Se trata, pues, de esfuerzos voluntaristas, como dice alDagmūmī, de autores que buscan asentar el género mediante un cambio de timón. Por ejemplo, nótese las palabras de Muhammad Barrāda en las que se alude a esta voluntad de los escritores marroquíes:

Ahora me parece que los creadores entre nosotros han comenzado a entender la necesidad de proporcionar algún tipo de particularidad a su producción tomada de la realidad marroquí, no de las mejores construcciones artísticas. Aquí se plantea la cuestión del vanguardismo: ¿tenemos que probar las formas 'completas' para que conseguir una 'superación' [taŷāwuz] de la literatura tradicional, o es que la cuestión tiene que ver en realidad con el desarrollo de la forma y el contenido a través del

${ }^{72}$ DAGMŪMĪ, Muhammad, al-Riwāya al-magribiyya..., 49. La cuestión de la hadāta es un lugar común en la teoría y la crítica literarias en Marruecos. En marzo de 1995 se celebró en la Facultad de Letras Benmesīk en Casablanca un congreso bajo el tema al-Riwāya al-magribiyya: as 'ilat al-hadāta, cuyas ponencias fueron publicadas por Dār al-Taqāfa en Casablanca en 1996; en líneas generales las ponencias consistían en estudios narratológicos relativos a la novela marroquí. Más tarde, 'Abd alRahīim al-'Allām publicó Su'āl al-ḥadāta fi-l-riwāya al-magribiyya (Casablanca, Afrīqiyāalal-Ŝarq, 1999) en el que treinta y ocho escritores marroquíes de diversos géneros contestaban más o menos brevemente a la pregunta “¿Puede hablarse actualmente de hadāta en la novela marroquí?”. 
logro de una producción vinculada estrechamente con el período o con los intereses de los lectores (...)? En otras palabras, la cuestión de la práctica cultural está planteada entre nosotros con fuerza. ${ }^{73}$

En cualquier caso, la impresión de que ocurren puntos de inflexión se produce precisamente por la escasez de obras; con la acumulación progresiva de novelas a partir de los ochenta, la evolución del género toma la forma de un desarrollo sin vuelcos.

Así, cuando 'Abd al-Hamīd 'Aqqār, ya en 2000, repasa rápidamente la producción novelística en Marruecos, comienza con Dafannā al-māậ̀ ("la primera novela en el sentido europeo publicada en Marruecos" ${ }^{\prime 74}$ ) y caracteriza la producción de los años ochenta y noventa por: 1) tratar la escritura "como un valor en sí mismo, como horizonte de lo probable y lo ficcional; 2) el recurso a la memoria, lo maravilloso y lo legendario; 3) el esfuerzo por domeñar la lengua, enriquecerla y renovarla; 4) los componentes autobiográficos; 5) cierto alejamiento del mero registro de acontecimientos y la insistencia en el reflejo de estos en la conciencia de los personajes, en "el conflicto de pensamientos y visiones del mundo"

Finalmente, como en toda definición temporal de períodos, no hay que dejar de tener en cuenta que en el desarrollo de los géneros literarios, las etapas se configuran en delimitaciones permeables, y no en compartimentos estancos. Como afirma Claudio Guillén, el período se constituye en un entrecruzamiento de corrientes, algunas procedentes de fases anteriores $\mathrm{y}$ otras recientes, unas que pueden languidecer o continuar, otras fluir y evolucionar hacia el futuro ${ }^{76}$.

${ }^{73} \hat{\text { S}} \bar{A} W U \bar{L}$, Bāwul [Paul Chaul], 'Alamāt min al-taqāfa al-magribiyya al-ḥadāta, Beirut, alMu'assasa al-'Arabiyya li-1-Dirāsāt wa-l-Naŝr, 1979, 18.

74 'AQQĀR, 'Abd al-Hamīd, al-Riwāya al-Magāribiyya ..., 24.

75 'AQQĀR, 'Abd al-Ḥamīd, al-Riwāya al-Magāribiyya ..., 24-25.

${ }^{76}$ GUILLÉN, Claudio, Entre lo uno..., 369. 